\title{
Synthesis, Characterization and Evaluation of the Cytotoxicity of Ni-Doped Zn(Se,S) Quantum Dots
}

\author{
Melissa Cruz-Acuña, ${ }^{1}$ Sonia Bailón-Ruiz, ${ }^{2,3}$ Carlos R. Marti-Figueroa, ${ }^{4}$ \\ Ricardo Cruz-Acuña, ${ }^{4}$ and Oscar J. Perales-Pérez ${ }^{2,5}$ \\ ${ }^{1}$ Industrial Biotechnology Program, University of Puerto Rico at Mayagüez, Mayagüez, PR 00680-9010, USA \\ ${ }^{2}$ Department of Chemistry, University of Puerto Rico at Mayagüez, Mayagüez, PR 00681-9019, USA \\ ${ }^{3}$ Department of Chemistry and Physics, University of Puerto Rico at Ponce, Ponce, PR 00716-9996, USA \\ ${ }^{4}$ Department of Chemical Engineering, University of Puerto Rico at Mayagüez, Mayagüez, PR 00681-9000, USA \\ ${ }^{5}$ Department of Engineering Science \& Materials, University of Puerto Rico at Mayagüez, Mayagüez, PR 00681-9044, USA
}

Correspondence should be addressed to Sonia Bailón-Ruiz; sonia.bailon@upr.edu

and Oscar J. Perales-Pérez; oscarjuan.perales@upr.edu

Received 30 August 2014; Accepted 5 January 2015

Academic Editor: Piaoping Yang

Copyright (C) 2015 Melissa Cruz-Acuña et al. This is an open access article distributed under the Creative Commons Attribution License, which permits unrestricted use, distribution, and reproduction in any medium, provided the original work is properly cited.

\begin{abstract}
Quantum dots (QDs) are semiconductor nanocrystals with desirable optical properties for biological applications, such as bioimaging and drug delivery. However, the potential toxicity of these nanostructures in biological systems limits their application. The present work is focused on the synthesis, characterization, and evaluation of the toxicity of water-stable Ni-doped Zn(Se,S) QDs. Also, the study of nondoped nanostructures was included for comparison purposes. Ni-doped nanostructures were produced from zinc chloride and selenide aqueous solutions in presence of 3-mercaptopropionic acid and Ni molar concentration of $0.001 \mathrm{M}$. In order to evaluate the potential cytoxicity of these doped nanostructures, human pancreatic carcinoma cells (PANC-1) were used as model. The cell viability was monitored in presence of Ni-doped $\mathrm{Zn}(\mathrm{Se}, \mathrm{S})$ QDs at concentrations ranging from $0 \mu \mathrm{g} / \mathrm{mL}$ to $500 \mu \mathrm{g} / \mathrm{mL}$ and light excited $\mathrm{Ni}$-doped $\mathrm{Zn}(\mathrm{Se}, \mathrm{S})$ nanostructures were evaluated at $50 \mu \mathrm{g} / \mathrm{mL}$. Results suggested that Ni-doped $\mathrm{Zn}(\mathrm{Se}, \mathrm{S})$ nanostructures were completely safe to PANC-1 when concentrations from $0 \mu \mathrm{g} / \mathrm{mL}$ to $500 \mu \mathrm{g} / \mathrm{mL}$ were used, whereas non-doped nanostructures evidenced toxicity at concentrations higher than $200 \mu \mathrm{g} / \mathrm{mL}$. Also, Ni-doped Zn(Se,S) QDs under light excitation do not evidence toxicity to PANC-1. These findings suggest strongly that $\mathrm{Zn}(\mathrm{Se}, \mathrm{S})$ nanostructures doped with nickel could be used in a safe manner in light-driving biological applications and drug delivery.
\end{abstract}

\section{Introduction}

Quantum dots (QDs) are semiconductor nanocrystals that exhibit tunable emission, high absorption coefficients and exceptional chemical and photostability [1-5]. Their corresponding optical properties can be tuned by altering their size, composition, and crystal array, and, moreover, make them suitable for biological purposes such as drug delivery and bio-imaging [6-8].

Traceable drug delivery is one of the most important applications of QDs because it provides the possibility of studying the pharmacokinetics and pharmacodynamics of potential drugs. In this way, nontoxic and photochemically stable QDs are needed in order to facilitate their functionalization and traceability by fluorescence [9].

Cd-based chalcogenides are the most studied quantum dots. However, there is a prevailing concern about the potential long-term toxicity they could provoke to biological systems, which limits their application for in vitro or small animal studies [10, 11]. For this reason, Zn-based materials are attractive substitutes that have no documented toxicity and still exhibit useful optical and chemical properties. Studies have reported that adding doping agents in trace concentrations to these $\mathrm{Zn}$-based nanostructures is possible to change their corresponding optical properties, increase the quantum yield, and also reduce or increase the emission 
traps $[12,13]$. Nickel (II) is a transition metal that represents an option as dopant agent for Zn-based QDs due to its atomic radius, which differs within the $10 \%$ limit (8.3\% of difference) to $\mathrm{Zn}^{2+}$ radius. Therefore, the substitution of $\mathrm{Zn}^{2+}$ atoms by $\mathrm{Ni}^{2+}$ atoms in the lattice is possible.

Frequently, QDs are synthesized in organic phase under refluxing, using coordinating solvents like trioctylphosphine oxide (TOPO), trioctylphosphine (TOP), and hexadecylamine [14-20]. Although, the reflux technique is highly reproducible and able to produce nanocrystals of narrow size distribution; the long time period required for the synthesis; the limited temperatures that can be achieved by this technique; and the generation of QDs stable in organic media limit its application. Furthermore, QDs stable in organic solvent are required for a ligand-exchange procedure in order to stabilize them in aqueous phase and can be used in biological applications $[17,18]$.

The Microwave irradiation technique has been recently used to produce nanoparticles because of its high reproducibility, less cost of energy and homogeneous heating capability which promote the generation of well monodispersed fluorescent nanoparticles. The possibility to produce water-stable nanoparticles using thiols agents under microwave irradiation is desirable to biomedical applications [19-24]. In this study, we have produced water-stable Nidoped $\mathrm{Zn}(\mathrm{Se}, \mathrm{S})$ nanocrystals of high-optical quality using 3-mercaptopropionic acid (MPA) under microwave irradiation. Ni-doped nanostructures characterized morphological, structurally and optically; were used in cytotoxicity studies using Human Pancreatic Carcinoma Cells (PANC1) as model. Nondoped nanostructures also were used as comparison purposes.

\section{Material and Methods}

2.1. Synthesis of Ni-Doped $Z n(S e, S)$ Quantum Dots. Ni-doped nanostructures were synthesized from initial zinc chloride (99.999\% trace metal basis), selenide and nickel chloride solutions in presence of 3-mercaptopropionic acid (MPA, 99.0\%) in a CEM Mars Xpress digestion system operated at $200 \mathrm{~W}$. All reactants were supply by Sigma-Aldrich. The selenide solution was prepared previously through the reduction of elemental selenium powder $(99.99 \%$ trace metal basis) with sodium bisulfide (>98\%). The molar ratio selenium/sodium bisulfide was $1.0 \mathrm{M} / 5.0 \mathrm{M}$ and the reduction was carried out at $100^{\circ} \mathrm{C}$ during 8 hours. Ni-doped Nanoparticles were prepared as follow: Zinc chloride solution was mixed with MPA in order to form a stable complex and to avoid the formation of zinc hydroxides. Then, nickel solution was added to the solution in order to attain molar concentrations from $0.0005 \mathrm{M}$ to $0.010 \mathrm{M}$. Finally, reduced selenide solution was added and the mixed solution was put into the vessel and heated using the microwave. The final molar ratio $\mathrm{Zn} / \mathrm{MPA} / \mathrm{Se}$ on all synthesis was estimated to be $1 / 2.4 / 0.04$. Also, for comparison purposes, nondoped nanostructures were synthesized using the same molar ratios $\mathrm{Zn} / \mathrm{MPA} / \mathrm{Se}$. The microwave power was set on $200 \mathrm{~W}$, preheating at $50^{\circ} \mathrm{C}$ for 15 minutes, increasing the temperature from 50 to $140^{\circ} \mathrm{C}$ for 6 minutes, and the actual reaction stage took place at $140^{\circ} \mathrm{C}$ during 30 minutes. Once the reaction concluded, the solution was cooled to room temperature, coagulated using 2-propanol, centrifuged, and resuspended in deionized water.

2.2. Characterization Techniques. A high-resolution TEM (HRTEM) analysis was made on a JEM-ARM200F and accomplished at $200 \mathrm{KV}$. A Shimadtzu $1800 \mathrm{UV} /$ Vis Spectrophotometer was used to obtain UV-Vis absorption measurements. The photoluminescence (PL) spectra were obtained using a Shimadtzu RF-5301 Spectrofluorometer with a $150 \mathrm{~W}$ Xenon lamp as excitation source. All measurements were performed at room temperature. With the purpose to study the desirable photostability of QDs needed to biological applications, nanostructures were irradiated under $302 \mathrm{~nm}$ during 60 minutes using a UV lamp with a power density of $10 \mathrm{~mW} \mathrm{~cm}^{-2}$.

2.3. Cell Culture. Human pancreatic carcinoma cells (PANC1) were purchased from ATCC (CRL number 1469) and cultured in DMEM (Dulbecco's Modified Eagle Medium) containing $10 \%(\mathrm{v} / \mathrm{v})$ bovine fetal serum and $50 \mu \mathrm{g} / \mathrm{L}$ gentamicin at temperature of $37^{\circ} \mathrm{C}$ under humidified air containing $5 \% \mathrm{CO}_{2}$.

2.4. Cytotoxicity Assays. The cell viability of PANC-1 cells exposed to Ni-doped nanostructures was determined by using a T4 Automatic Cell Counter. PANC-1 cells were cultured in a CellBind $25 \mathrm{~cm}^{2}$ flask until it was observed $80 \%$ of confluence. Cells were trypsinized, homogenized, added to 96-well plate and waited until cells attached. Nidoped nanostructures were re-suspended in PBS and added to each well to achieve final concentrations ranging from 0 to $500 \mu \mathrm{g} / \mathrm{mL}$. The incubation time was 48 hours. Finally, cells were trypsinized and mixed with trypan blue to measure the corresponding cell viability.

The viability of PANC-1 cells under light-irradiated Nidoped nanostructures was investigated. Ni-doped nanostructures dispersed in PBS were added to PANC-1 cells that were seeded in 48-well plates in order to achieve a final concentration of $50 \mu \mathrm{g} / \mathrm{mL}$. Cells in presence of Ni-doped nanostructures were irradiated using a $302 \mathrm{~nm}$-UV lamp (8 watts, power density of $10 \mathrm{~mW} \mathrm{~cm}^{-2}$ ) up to 60 minutes. The cell viability was assessed after 4 hours of post-incubation at $37^{\circ} \mathrm{C}$ in humidified air containing $5 \% \mathrm{CO}_{2}$.

Nondoped nanostructures ( $\mathrm{ZnSeS}$ QDs) and control samples (only cells) were evaluated in the same conditions to $\mathrm{Ni}$-doped nanostructures as comparison purposes.

\section{Results and Discussion}

3.1. Structural and Morphological Characterization. X-ray Diffraction (XRD) patterns of synthesized nondoped and $\mathrm{Ni}$ doped nanostructures suggest the formation of zinc blende structures (Figure 1). The presence of the diffraction peaks between those $2 \theta$ angles corresponding to bulk ZnSe (JCPDS card 80-0021) and ZnS (JCPDS card 77-2100) indicates the development of a solid solution of the type $\mathrm{Zn}(\mathrm{Se}, \mathrm{S})$ for 


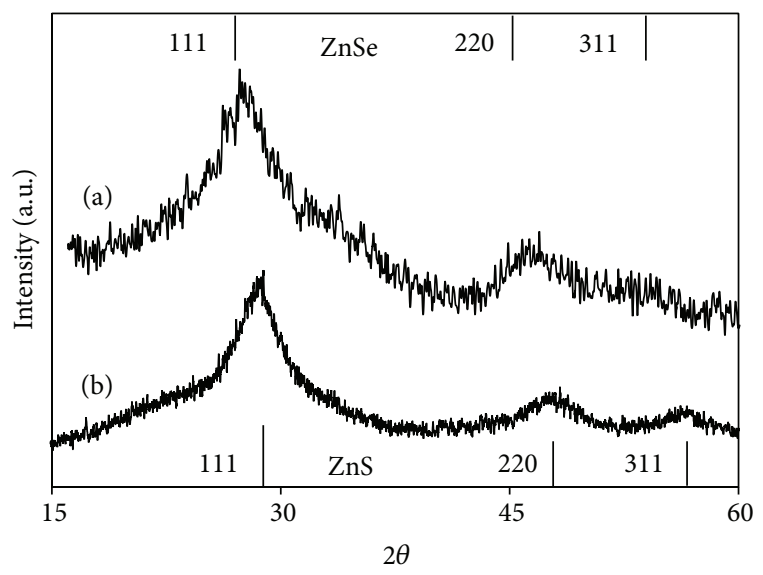

FIgURE 1: X-ray diffraction spectrum for nondoped $\mathrm{Zn}(\mathrm{Se}, \mathrm{S})$ QDs (a) and 0.001 M Ni-doped Zn(Se,S) QDs (b) synthesized in presence of MPA at $140^{\circ} \mathrm{C}$. Lines correspond to the position of $\mathrm{ZnSe}$ (top) and ZnS (bottom) bulk peaks.

nondoped and Ni-doped nanostructures. The presence of nickel in trace concentration $(0.001 \mathrm{M})$ into the lattice does not change the original crystalline structure type blenda (Figure 1(b)). The particle sizes for nondoped and $\mathrm{Ni}$-doped nanostructures were of $2.1 \pm 0.2 \mathrm{~nm}$ and $2.8 \pm 0.3 \mathrm{~nm}$, respectively, which were estimated from X-ray line broadening using the Debye-Scherrer's relationship. The slight increase of crystal size observed in $\mathrm{Ni}$-doped nanostructures is according to observations found by Cong et al., where $\mathrm{Zn}$-based nanoparticles increase its size in presence of nickel as dopant agent [25]. The ionic radius of $\mathrm{Ni}^{2+}(0.55 \AA)$ is slightly smaller than that of the $\mathrm{Zn}^{2+}(0.60 \AA)$ ion in tetrahedral coordination, which suggests the factible substitution of the $\mathrm{Zn}^{2+}$ ion by the $\mathrm{Ni}^{2+}$ and it is incorporation into the lattice structure [25]. The lattice parameter was estimated to be 0.539 and 0.556 , for Ni-doped nanostructures and nondoped nanostructures respectively, which falls in-between the values for bulk $\mathrm{ZnSe}$ $(0.567 \mathrm{~nm})$ and $\mathrm{ZnS}(0.538 \mathrm{~nm})$. The estimated values of the lattice parameters confirm the generation of ternary solid solutions of the $\mathrm{Zn}(\mathrm{S}, \mathrm{Se})$ type where the incorporation of $\mathrm{Ni}$ species did not affect the structural array.

The presence of nickel into the synthesized samples was corroborated by ICP-MS. The $\mathrm{Zn} / \mathrm{Ni}$ molar ratios in $\mathrm{Ni}$ doped nanostructures were $44 \pm 3$. Also, Molar ratios of $\mathrm{Zn} / \mathrm{Se}$ for Ni-doped nanostructures were $3.3 \pm 0.2$.

The small size under $4 \mathrm{~nm}$ of the synthesized nanostructures was corroborated with the HRTEM images (Figures 2 and 3). The images evidence that nondoped and Ni-doped nanostructures were crystallines. The electron diffractions patterns for Figure 2 (bottom) and Figure 3 (rigth) also, show the (111), (220), (311) planes that affirm the cubic $\mathrm{Zn}(\mathrm{Se}, \mathrm{S})$ structure array in these synthesized nanostructures.

The generation of the nanostructures can be explained by initial fast reaction between $\mathrm{Zn}$ and selenide species, which forms the $\mathrm{ZnSe}$ nanostructures. In this way, some zinc ions should be replaced by nickel ions. Then, the sulfide species formed by the thermal decomposition of MPA, enter into the $\mathrm{ZnSe}$ lattice forming a solid solution of $\mathrm{Zn}(\mathrm{Se}, \mathrm{S})$.
Subsequently, the adsorption of nonreacted thiol species by the surface of the nanostructures, would be establishing a net negative surface charge that prevents the nanocrystals from aggregation $[19,24]$. The presence of MPA forming a bridging bidentate complex with zinc ions on the Ni-doped QDs surface was confirmed by FT-IR (see Supplementary Material available online at http://dx.doi.org/10.1155/2015/702391).

3.2. Optical Properties. Figure 4 corresponds to the UV-Vis absorption spectra for $\mathrm{Ni}$-doped $\mathrm{Zn}(\mathrm{Se}, \mathrm{S}) \mathrm{QD}$ s synthesized in presence of MPA at nickel molar concentrations ranged from $0.0005 \mathrm{M}$ to $0.010 \mathrm{M}$. There was not detected a remarkable effect of the nickel concentrations on the position of the absorption peak $(\sim 373 \mathrm{~nm})$; therefore, a minimum variation in the nanocrystals size can be suggested. The estimated band gap energy values were $3.1 \mathrm{eV}$ for all samples synthesized in presence of $\mathrm{Ni}$ molar concentrations from $0.0005 \mathrm{M}$ to $0.010 \mathrm{M}$. The estimated band gap values higher than $2.7 \mathrm{eV}$ (bulk) suggest a quantum confinement effect in the synthesized samples.

Figure 5 corresponds to the photoluminescence spectra of $\mathrm{Ni}$-doped $\mathrm{Zn}(\mathrm{Se}, \mathrm{S})$ nanostructures synthesized in presence of MPA at nickel molar concentrations ranged from $0.0005 \mathrm{M}$ to 0.010 M. A main PL peak centered at $\sim 400 \mathrm{~nm}$ and a broad peak at $470 \mathrm{~nm}$ for all doped samples are evident in these results. Samples synthesized at $0.001 \mathrm{M}$ nickel showed the highest PL intensity at $\sim 400 \mathrm{~nm}$ and a quenching in the photoluminescence was observed when nickel concentrations higher than $0.001 \mathrm{M}$ were used. This drop in the luminescence intensity can be a consequence of the preferential formation of NiS. Previous reports have evidenced that NiS should act as nonradiative recombination centers and reduce the number of $\mathrm{Ni}^{+2}$ ions available that are optically active luminescence centers in doped nanocrystals [26].

Figure 6 shows the UV-Vis (left) and PL (right) spectra for nondoped $\mathrm{Zn}(\mathrm{Se}, \mathrm{S})$ QDs and Ni-doped $\mathrm{Zn}(\mathrm{Se}, \mathrm{S})$ QDs synthesized at $140^{\circ} \mathrm{C}$ using MPA. The slightly red shift $(\sim 373 \mathrm{~nm})$ observed in the UV-Vis absorption spectra for $\mathrm{Ni}$-doped $\mathrm{Zn}(\mathrm{Se}, \mathrm{S})$ QDs in comparison to the nondoped $\mathrm{Zn}(\mathrm{Se}, \mathrm{S})$ QDs $(\sim 348 \mathrm{~nm})$ suggests that Ni-doped $\mathrm{Zn}(\mathrm{Se}, \mathrm{S})$ QDs have a size slightly higher than nondoped $\mathrm{Zn}(\mathrm{Se}, \mathrm{S})$ QDs. The band gaps for each sample estimated according to the Tauc's relation were 3.3 and $3.1 \mathrm{eV}$ for nondoped $\mathrm{Zn}(\mathrm{Se}, \mathrm{S})$ QDs and Ni-doped $\mathrm{Zn}(\mathrm{Se}, \mathrm{S}) \mathrm{QDs}$, respectively [27]. These results are in according to Cong et al., where they observed the decrease in the band gap of nanostructures doped with nickel [25].

The position of the emission bands (Figure 6-right) is very similar ( 400) for pure and doped QDs $(\mathrm{Zn}(\mathrm{Se}, \mathrm{S})$ QDs and Ni-doped $\mathrm{Zn}(\mathrm{Se}, \mathrm{S})$ QDs synthesized in presence of MPA). However, the broad band at $470 \mathrm{~nm}$ attributed to emission trap was significantly reduced in presence of nickel. In this way, the variation of the main/trap emission intensities ratios for pure QDs and 0.001 M Ni-doped QDs were 1.5 and 3.5 , respectively. These values suggested that the nickel in adequate concentrations enhances the intensity of the band gap emission peak $(\sim 400 \mathrm{~nm})$ and decreases the intensity of the emission traps $(\sim 470 \mathrm{~nm})$. 

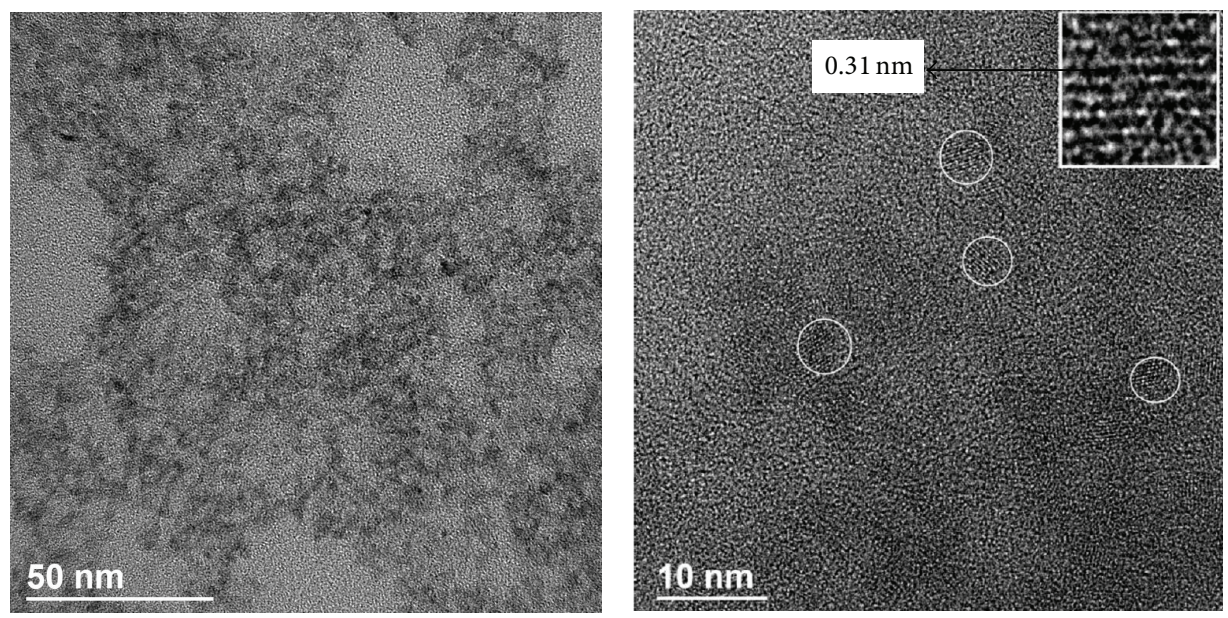

(a)

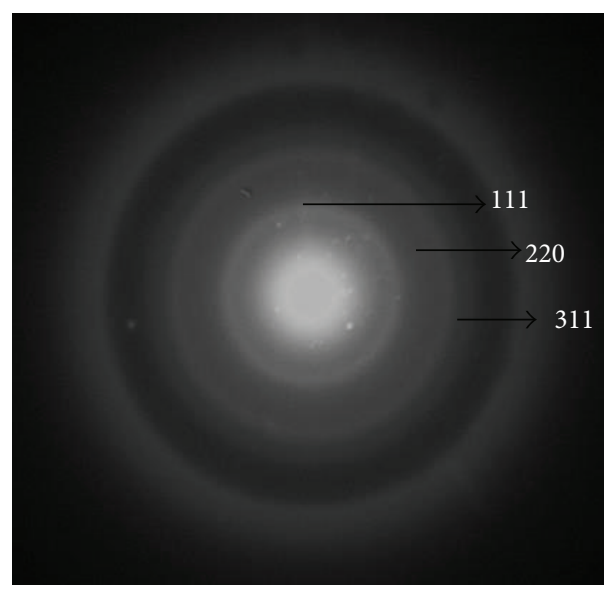

(b)

FIgURE 2: HRTEM of Ni-doped $\mathrm{Zn}(\mathrm{Se}, \mathrm{S})$ quantum dots synthesized in presence of MPA (top) and ED pattern (bottom).

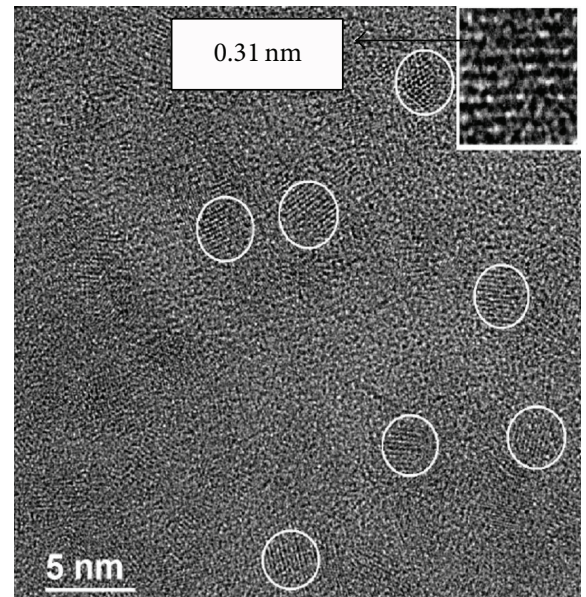

(a)

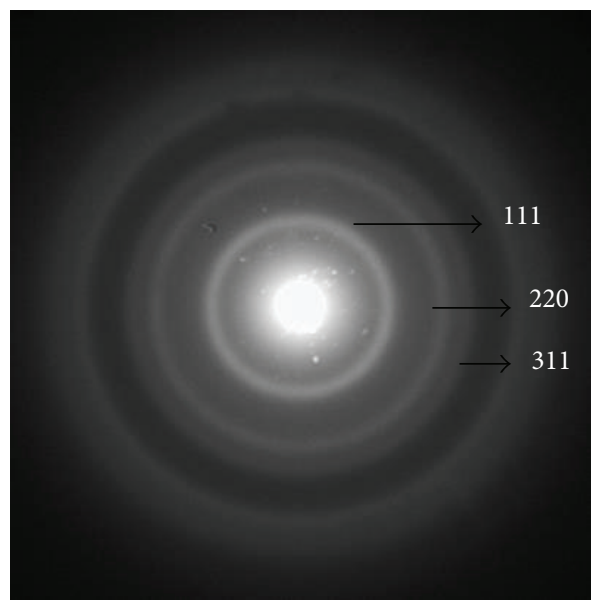

(b)

FIGURE 3: HRTEM of nondoped $\mathrm{Zn}(\mathrm{Se}, \mathrm{S})$ quantum dots synthesized in presence of MPA (left) and ED pattern (right). 


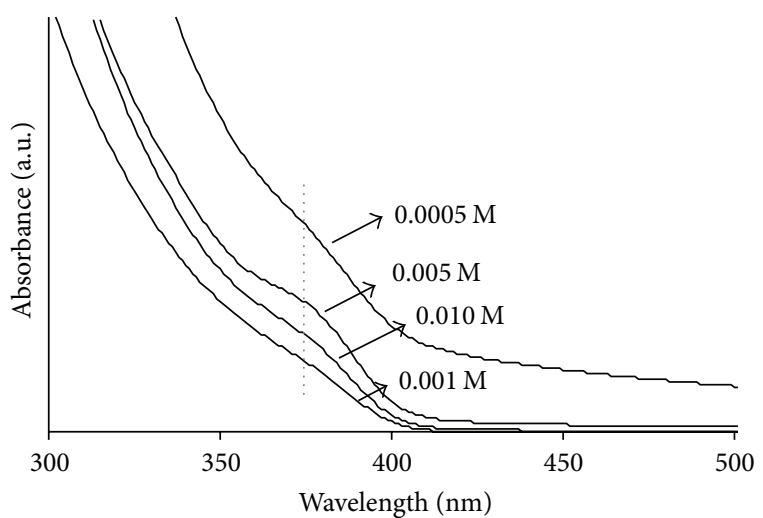

Figure 4: UV-Vis absorption spectra of Ni-doped $\mathrm{Zn}(\mathrm{Se}, \mathrm{S})$ QDs at various molar concentrations of nickel.

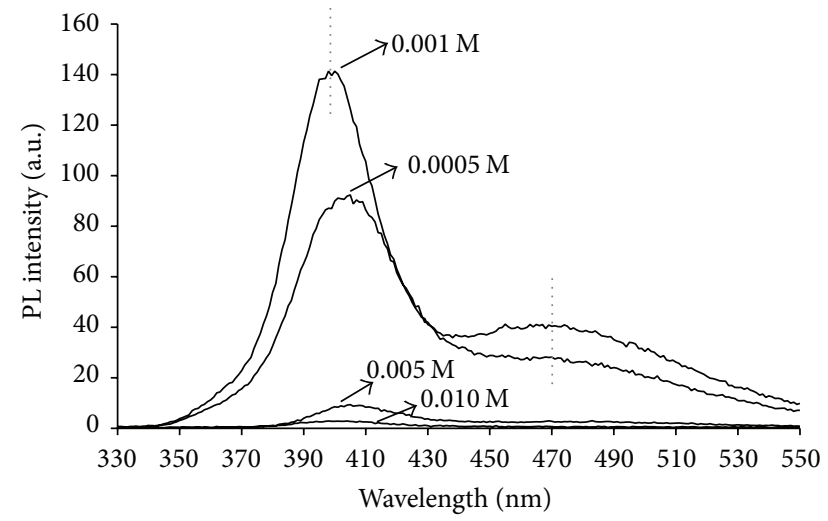

FIgURE 5: PL emission spectra of Ni-doped $\mathrm{Zn}(\mathrm{Se}, \mathrm{S}) \mathrm{QDs}$ at various molar concentrations of nickel. The excitation wavelength was $311 \mathrm{~nm}$.

3.3. Photostability Assays. An essential consideration to extend the use of QDs to biological applications is that they can maintain a stable luminescence under light excitation. The variation of the intensity of the main emission peak was evaluated when nondoped and $\mathrm{Ni}$-doped $\mathrm{Zn}(\mathrm{Se}, \mathrm{S})$ QDs were subjected to UV (302 nm)-irradiation at different time points. The observed luminescence fluctuation should be an indicative of the photostability of produced nanocrystals.

Figure 7 shows the variation of the normalized emission intensity [(intensity after UV exposure/initial intensity in water) $\times 100$ ] of the QDs as a function of the UV-irradiation time. QDs were suspended in water or PBS and UV-irradiated for: $0 \mathrm{~min}$ (control test), $15 \mathrm{~min}, 30 \mathrm{~min}$ or $60 \mathrm{~min}$ using a lamp with a power density of $10 \mathrm{~mW} \mathrm{~cm}^{-2}$. The normalized main emission peak intensity for the control test of QDs suspended in deionized water was $98 \%$ for nondoped $\mathrm{Zn}(\mathrm{Se}, \mathrm{S})$ QDs and 99\% for Ni-doped $\mathrm{Zn}(\mathrm{Se}, \mathrm{S}) \mathrm{QDs}$. QDs re-suspended in PBS achieved normalized emission intensities of $93 \pm 3 \%$ and $85 \pm 2 \%$, for nondoped $\mathrm{Zn}(\mathrm{Se}, \mathrm{S}) \mathrm{QDs}$ and $\mathrm{Ni}$-doped $\mathrm{Zn}(\mathrm{Se}, \mathrm{S})$ QDs respectively, at 0 minutes of UV (302 nm)irradiation. These results demonstrated excellent stabilities of nondoped and Ni-doped QDs in either deionized water or PBS.

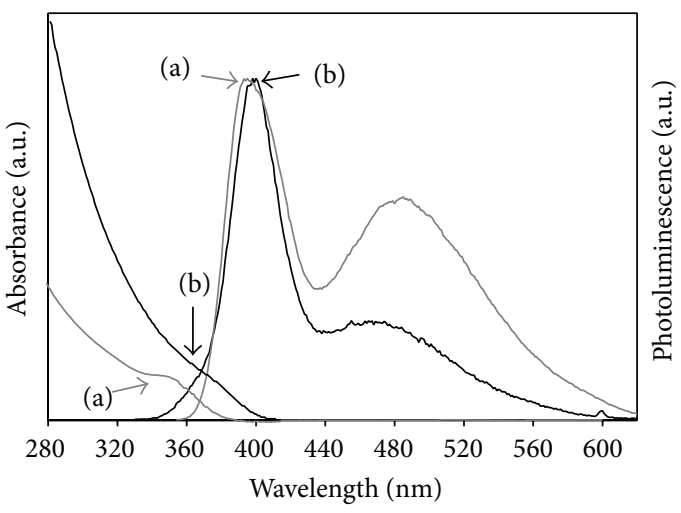

FIGURE 6: UV-Vis absorption (left) and PL emission (right) spectra $\mathrm{Zn}(\mathrm{Se}, \mathrm{S})$ QDs (a) and Ni-doped $\mathrm{Zn}(\mathrm{Se}, \mathrm{S})$ QDs (b). The excitation wavelength was $311 \mathrm{~nm}$.

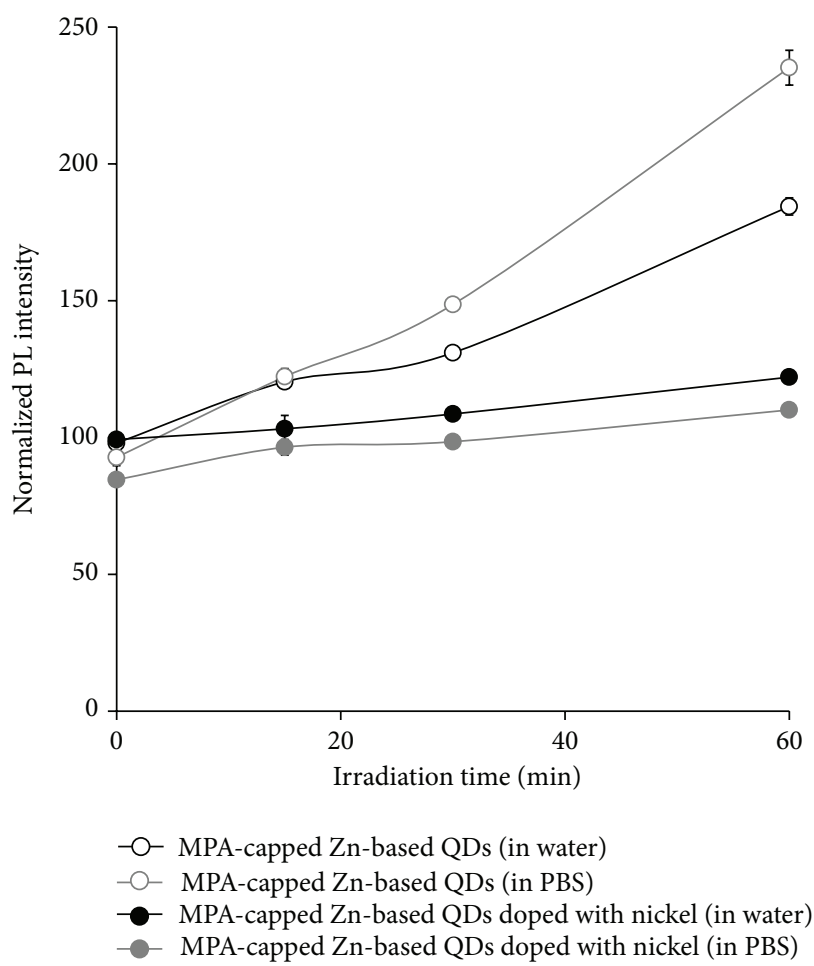

Figure 7: Normalized photoluminescence of nondoped $\mathrm{Zn}(\mathrm{Se}, \mathrm{S})$ and Ni-doped $\mathrm{Zn}(\mathrm{Se}, \mathrm{S})$ QDs in water or PBS, after UV (302 nm)irradiation.

A notable increase in the normalized emission intensity after $60 \mathrm{~min}$ of UV irradiation was observed on nondoped $\mathrm{Zn}(\mathrm{Se}, \mathrm{S})$ QDs and Ni-doped $\mathrm{Zn}(\mathrm{Se}, \mathrm{S})$ QDs suspended in both, water or PBS, compared to the control test. The intensity increased $88 \%$ on nondoped $\mathrm{Zn}(\mathrm{Se}, \mathrm{S})$ QDs and $23 \%$ on $\mathrm{Ni}$-doped $\mathrm{Zn}(\mathrm{Se}, \mathrm{S})$ QDs suspended in water after 60 minutes of UV-irradiation. Also, the PL intensities for the same QDs resuspended in PBS, were enhanced in 153\% and $29 \%$, respectively. It is believed that this photoinduced enhancement in the PL should be associated to the "oxygen passivation" of the nanocrystals surface [21]. The presence of 


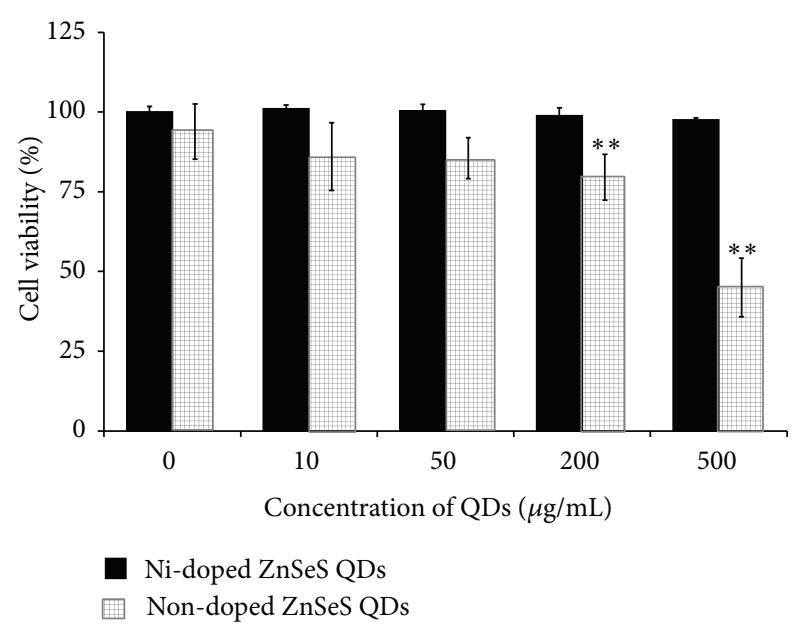

FIGURE 8: Viability percent of cells exposed to QDs at 0 to $500 \mu \mathrm{g} / \mathrm{mL}$ after 48 hours of exposure.

these species on the nanostructure's surface should passivate the surface states that are not coated by MPA, promoting the increase on the photoluminescence of the QD [21]. The latter mentioned results demonstrated a great photostability of nondoped $\mathrm{Zn}(\mathrm{Se}, \mathrm{S}) \mathrm{QDs}$ and Ni-doped $\mathrm{Zn}(\mathrm{Se}, \mathrm{S})$ QDs under UV irradiation, an important consideration for biological applications.

3.4. Intrinsic Cytotoxicity of Ni-Doped Nanostructures. The data shown in Figure 8 revealed that Ni-doped $\mathrm{Zn}(\mathrm{Se}, \mathrm{S})$ QDs were completely safe to PANC-1 cells. The viability of the PANC-1 exposed to Ni-doped $\mathrm{Zn}(\mathrm{Se}, \mathrm{S})$ QDs was nearly $100 \%$ at $500 \mu \mathrm{g} / \mathrm{mL}$ of concentration. Contrarily, nondoped $\mathrm{Zn}(\mathrm{Se}, \mathrm{S}) \mathrm{QDs}$ started to be toxic, affecting significantly the viability of the cells, at $200 \mu \mathrm{g} / \mathrm{mL}$ and higher concentrations $(p<0.01)$. The cell viability of nondoped $\mathrm{Zn}(\mathrm{Se}, \mathrm{S}) \mathrm{QDs}$ and Ni-doped $\mathrm{Zn}(\mathrm{Se}, \mathrm{S}) \mathrm{QDs}$ at $200 \mu \mathrm{g} / \mathrm{mL}$ were $80 \pm 7 \%$ and $98 \pm$ $4 \%$, respectively.

The observed toxicity for nondoped Zn(Se,S) QDs could suggest the production of reactive oxygen species in biological media. Li et al. [28] have suggested the promoted generation of cytotoxic reactive oxygen species or free radicals (ROS) depending on the surface features of the nanocrystals [28]. It has been previously demonstrated that certain types of QDs could produce ROS even without light excitation [29]. Also, it had been reported that the production free radicals is promoted by the generation of the pair electronhole (exciton) and migration of this exciton to the quantum dots surface in order to reduce the oxygen and generate the radical peroxide or oxidize the water and produce the $\mathrm{OH}$ radical. If the exciton is recombined before its migration to the quantum dots surface, the generation of free radicals does not happen. In this way, the presence of nickel in the quantum dots structure should promote the recombination of the pair electron-hole before their interaction with surface species like oxygen or water. As a consequence the presence of nickel avoided the production of ROS.

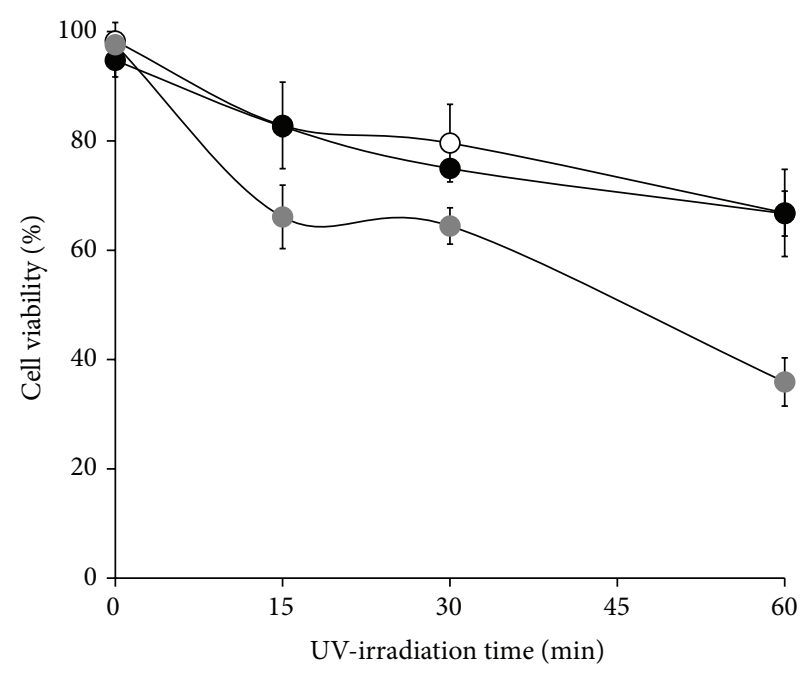

$$
\begin{aligned}
& \text { - Cells } \\
& \text { - Ni-doped ZnSeS QDs }
\end{aligned}
$$

FIGURE 9: Effect of UV irradiation time on PANC-1 viability. The final concentration of the nondoped and Ni-doped $\mathrm{Zn}(\mathrm{Se}, \mathrm{S}) \mathrm{QDs}$ was $50 \mu \mathrm{g} / \mathrm{mL}$. Blanks were cells incubated with no QDs. Data showed the mean value \pm SD of three independent experiments $(n=3)$.

3.5. Cytotoxicity of Ni-Doped Nanostructures Activated by Light. The cytotoxicity of nondoped $\mathrm{Zn}(\mathrm{Se}, \mathrm{S}) \mathrm{QDs}$ and Ni-doped ZnSeS QDs at concentrations of $50 \mu \mathrm{g} / \mathrm{mL}$ was evaluated on PANC-1 at different intervals of UV-exposure (Figure 9). The PANC-1 viability was not affected by the presence of UV-irradiated Ni-doped $\mathrm{Zn}(\mathrm{Se}, \mathrm{S})$ QDs after 60 minutes of UV irradiation. The viability of the PANC-1 exposed to Ni-doped $\mathrm{Zn}(\mathrm{Se}, \mathrm{S})$ QDs was $92 \pm 3 \%$ after a period of 60 minutes of UV irradiation. The cell viability for the control test (only cells irradiated with UV during 60 minutes) was $90 \pm 3 \%$. In this way, the cell viability for nondoped $\mathrm{Zn}(\mathrm{Se}, \mathrm{S})$ QDS decreases as much as $36 \pm 4 \%$ after $60 \mathrm{~min}$ under UV-irradiation. The observed increase in cytotoxicity for nondoped $\mathrm{Zn}(\mathrm{Se}, \mathrm{S})$ QDs could be explained by the production of toxic species like singlet oxygen and ROS induced by the UV excitation. UV-irradiated Ni-doped Nanostructures at high concentration $(500 \mu \mathrm{g} / \mathrm{mL})$ were also evaluated, evidenced absence of toxicity to PANC-1.

\section{Conclusions}

Water-stable Ni-doped $\mathrm{Zn}(\mathrm{Se}, \mathrm{S})$ QDs and nondoped $\mathrm{Zn}(\mathrm{Se}, \mathrm{S}) \mathrm{QDs}$ were synthesized under microwave irradiation at $140^{\circ} \mathrm{C}$.

It was found that Ni-doped $\mathrm{Zn}(\mathrm{Se}, \mathrm{S}) \mathrm{QDs}$ are less toxic than nondoped $\mathrm{Zn}(\mathrm{Se}, \mathrm{S}) \mathrm{QDs}$ to PANC-1. The viability of PANC-1 exposed to Ni-doped QDs was nearly $100 \%$ at $500 \mu \mathrm{g} / \mathrm{mL}$ of concentration. However, the viability of PANC1 exposed to nondoped QDs was decreased when nondoped QDs at concentrations of $200 \mu \mathrm{g} / \mathrm{mL}$ and higher were used. Furthermore, UV-irradiated Ni-doped nanostructures 
$(50 \mu \mathrm{g} / \mathrm{mL})$ did not evidence toxicity to cancer cells. The latter mentioned results suggest the potential use of Ni-doped $\mathrm{Zn}(\mathrm{Se}, \mathrm{S}) \mathrm{QDs}$ in biological applications.

\section{Conflict of Interests}

The authors declare that there is no conflict of interests regarding the publication of this paper.

\section{Acknowledgment}

This work was financially supported by The National Science Foundation under Grant no. HRD 0833112 (CREST program).

\section{References}

[1] C. B. Murray, M. Nirmal, D. J. Norris, and M. G. Bawendi, "Synthesis and structural characterization of II-VI semiconductor nanocrystallites (quantum dots)," Zeitschrift für Physik D Atoms, Molecules and Clusters, vol. 26, no. 1, pp. 231-233, 1993.

[2] S. A. Empedocles, D. J. Norris, and M. G. Bawendi, "Photoluminescence spectroscopy of single CdSe nanocrystallite quantum dots," Physical Review Letters, vol. 77, no. 18, pp. 3873-3876, 1996.

[3] C. J. Murphy and J. L. Coffer, "Quantum dots: a primer," Applied Spectroscopy, vol. 56, no. 1, pp. 16A-27A, 2002.

[4] S. Bailon-Ruiz, L. Alamo-Nole, and O. Perales-Perez, "Synthesis and surface functionalization of water-soluble quantum dots," Current Nanoscience, vol. 8, no. 2, pp. 202-207, 2012.

[5] H. Weller, "Colloidal semiconductor Q-particles: chemistry in the transition region between solid state and molecules," Angewandte Chemie International Edition in Englis, vol. 32, no. 1, pp. 41-53, 1993.

[6] A. P. Alivisatos, "Semiconductor clusters, nanocrystals, and quantum dots," Science, vol. 271, no. 5251, pp. 933-937, 1996.

[7] A. P. Alivisatos, "Perspectives on the physical chemistry of semiconductor nanocrystals," The Journal of Physical Chemistry, vol. 100, no. 31, pp. 13226-13239, 1996.

[8] J. Yuan, W. Guo, X. Yang, and E. Wang, "Anticancer drug-DNA interactions measured using a photoinduced electron-transfer mechanism based on luminescent quantum dots," Analytical Chemistry, vol. 81, no. 1, pp. 362-368, 2009.

[9] L. Qi and X. Gao, "Emerging application of quantum dots for drug delivery and therapy," Expert Opinion on Drug Delivery, vol. 5, no. 3, pp. 263-267, 2008.

[10] R. Bakalova, H. Ohba, Z. Zhelev et al., "Quantum dot anti-CD conjugates: are they potential photosensitizers or potentiators of classical photosensitizing agents in photodynamic therapy of cancer?" Nano Letters, vol. 4, no. 9, pp. 1567-1573, 2004.

[11] J. Lee, K. Ji, J. Kim et al., "Acute toxicity of two CdSe/ZnSe quantum dots with different surface coating in Daphnia magna under various light conditions," Environmental Toxicology, vol. 25, no. 6, pp. 593-600, 2010.

[12] S. J. Pearton, D. P. Norton, K. Ip, Y. W. Heo, and T. Steiner, "Recent progress in processing and properties of $\mathrm{ZnO}$," Progress in Materials Science, vol. 50, no. 3, pp. 293-340, 2005.

[13] Z. Deng, F. L. Lie, S. Shen, I. Ghosh, M. Mansuripur, and A. J. Muscat, "Water-based route to ligand-selective synthesis of $\mathrm{ZnSe}$ and $\mathrm{Cd}$-doped $\mathrm{ZnSe}$ quantum dots with tunable ultraviolet A to blue photoluminescence," Langmuir, vol. 25, no. 1, pp. 434-442, 2009.

[14] N. Pradhan and X. Peng, "Efficient and color-tunable Mndoped ZnSe nanocrystal emitters: control of optical performance via greener synthetic chemistry," Journal of the American Chemical Society, vol. 129, no. 11, pp. 3339-3347, 2007.

[15] C. B. Murray, D. J. Norris, and M. G. Bawendi, "Synthesis and characterization of nearly monodisperse $\mathrm{CdE}(\mathrm{E}=$ sulfur, selenium, tellurium) semiconductor nanocrystallites," Journal of American Chemical Society, vol. 115, no. 19, pp. 8706-8715, 1993.

[16] X. Peng, J. Wickham, and A. P. Alivisatos, "Kinetics of II-VI and III-V colloidal semiconductor nanocrystal growth: Focusing of size distributions," Journal of the American Chemical Society, vol. 120, no. 21, pp. 5343-5344, 1998.

[17] W. W. Yu, L. Qu, W. Guo, and X. Peng, "Experimental determination of the extinction coefficient of CdTe, CdSe, and CdS nanocrystals," Chemistry of Materials, vol. 15, no. 14, pp. 28542860, 2000.

[18] J. M. Costa-Fernández, R. Pereiro, and A. Sanz-Medel, "The use of luminescent quantum dots for optical sensing," Trends in Analytical Chemistry, vol. 25, no. 3, pp. 207-218, 2006.

[19] S. Kim and M. G. Bawendi, "Oligomeric ligands for luminescent and stable nanocrystal quantum dots," Journal of the American Chemical Society, vol. 125, no. 48, pp. 14652-14653, 2003.

[20] S.-W. Kim, S. Kim, J. B. Tracy, A. Jasanoff, and M. G. Bawendi, "Phosphine oxide polymer for water-soluble nanoparticles," Journal of the American Chemical Society, vol. 127, no. 13, pp. 4556-4557, 2005.

[21] H. Qian, X. Qiu, L. Li, and J. Ren, "Microwave-assisted aqueous synthesis: a rapid approach to prepare highly luminescent $\mathrm{ZnSe}(\mathrm{S})$ alloyed quantum dots," Journal of Physical Chemistry $B$, vol. 110, no. 18, pp. 9034-9040, 2006.

[22] S. J. Bailon-Ruiz, O. Perales-Perez, S. P. Singh, and P. M. Voyles, "Effect of doping on the structural and optical properties of microwave-assisted synthesis of ZnSe@ZnS core-shell quantum dots," Materials Research Society Symposium Proceedings, vol. 1207, Article ID N10-61, pp. 1-6, 2010.

[23] Y. Hu, Y. Liu, H. Qian, Z. Li, and J. Chen, "Coating colloidal carbon spheres with CdS nanoparticles: microwave-assisted synthesis and enhanced photocatalytic activity," Langmuir, vol. 26, no. 23, pp. 18570-18575, 2010.

[24] J. A. Gerbec, D. Magana, A. Washington, and G. F. Strouse, "Microwave-enhanced reaction rates for nanoparticle synthesis," Journal of the American Chemical Society, vol. 127, no. 45, pp. 15791-15800, 2005.

[25] C. J. Cong, J. H. Hong, Q. Y. Liu, L. Liao, and K. L. Zhang, "Synthesis, structure and ferromagnetic properties of Ni-doped ZnO nanoparticles," Solid State Communications, vol. 138, no. 10-11, pp. 511-515, 2006.

[26] P. Yang, M. Lü, C. F. Song, G. Zhou, D. Xu, and D. R. Yuan, "Photoluminescence characteristics of NiS nanocrystallites embedded in sol-gel silica xerogel," Journal of Physics and Chemistry of Solids, vol. 63, no. 11, pp. 2047-2051, 2002.

[27] J. Tauc, Amorphous and Liquid Semiconductors, Springer, New York, NY, USA, 1974.

[28] K. G. Li, J. T. Chen, S. S. Bai et al., "Intracellular oxidative stress and cadmium ions release induce cytotoxicity of unmodified cadmium sulfide quantum dots," Toxicology in Vitro, vol. 23, no. 6, pp. 1007-1013, 2009. 
[29] A. Hoshino, K. Fujioka, T. Oku et al., "Physicochemical properties and cellular toxicity of nanocrystal quantum dots depend on their surface modification," Nano Letters, vol. 4, no. 11, pp. 2163-2169, 2004. 

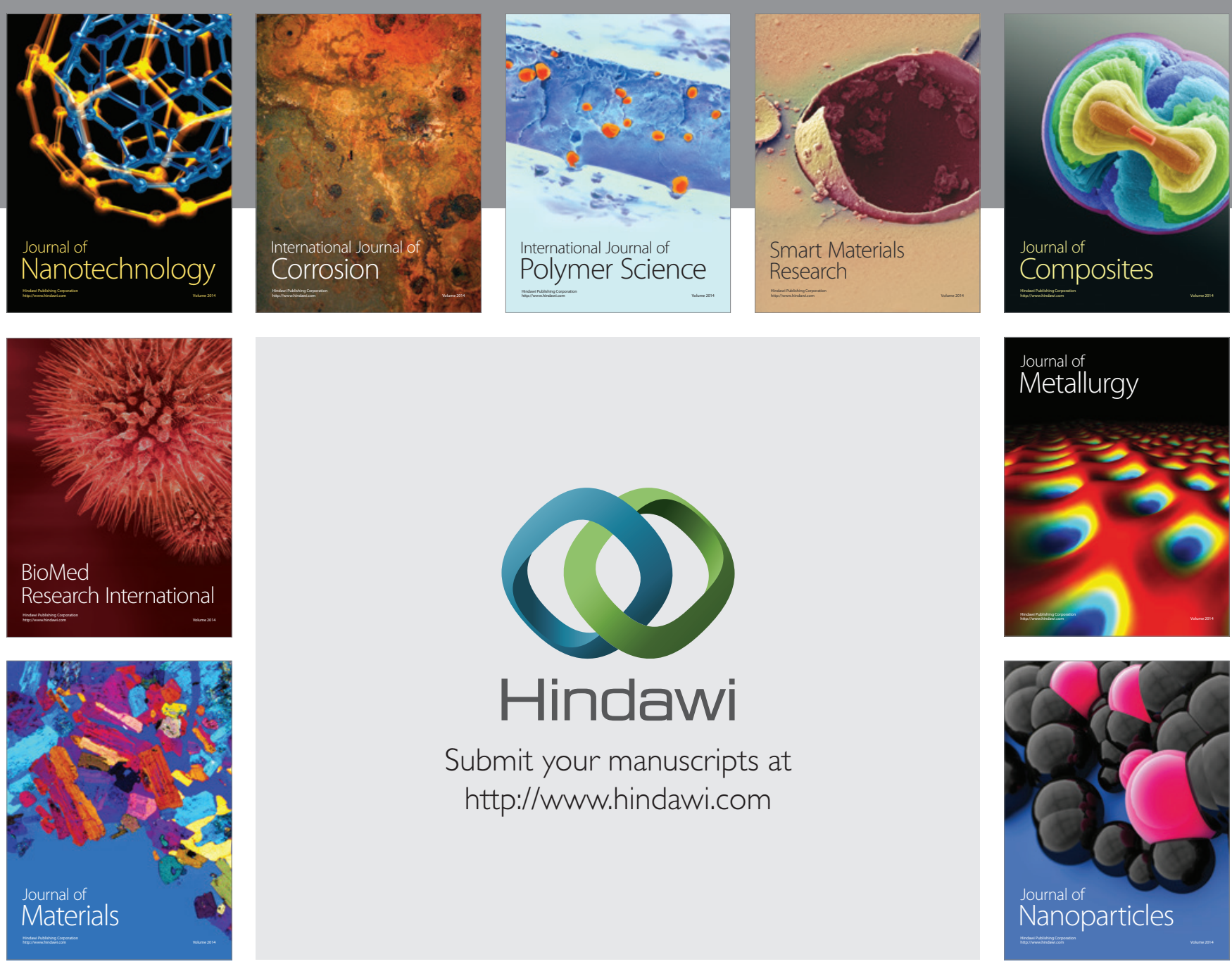

Submit your manuscripts at http://www.hindawi.com
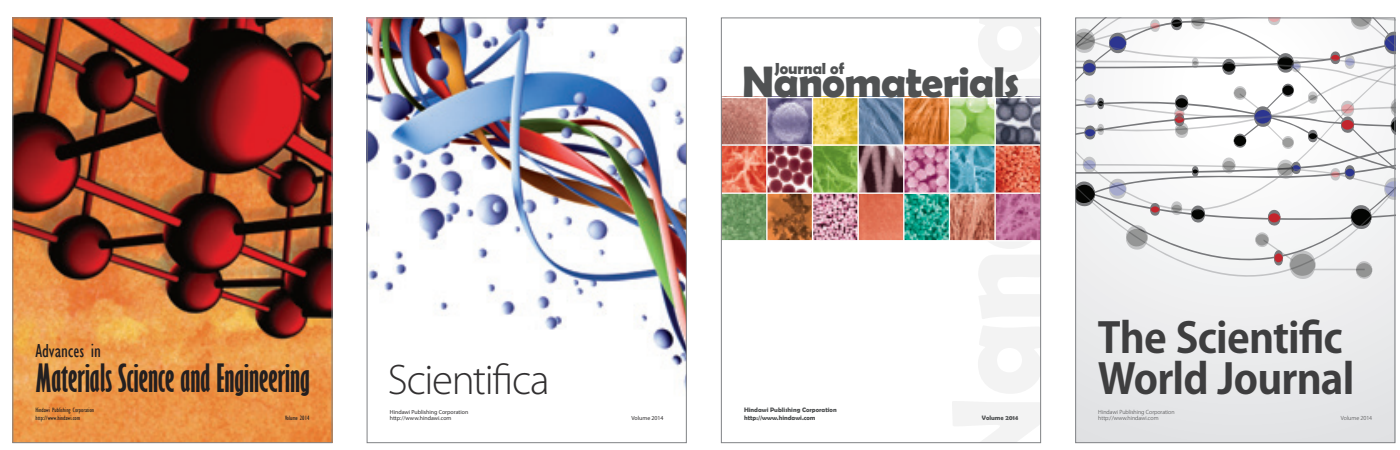

\section{The Scientific World Journal}
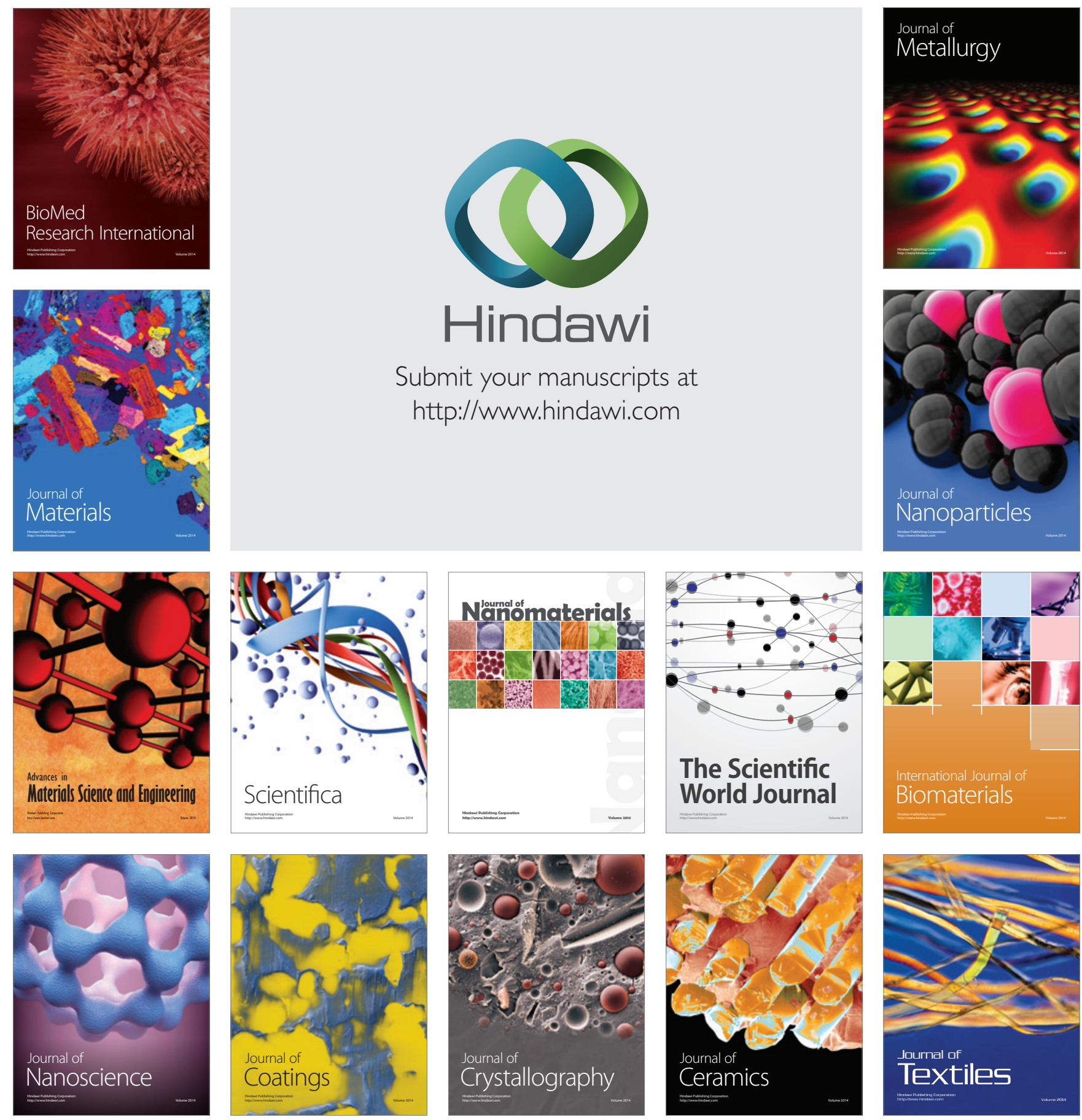